\title{
33. SOBRE UNA HIPOTÉTICA REFORMA DE LA POTESTAD DE DISOLUCIÓN DE LAS CÁMARAS LEGISLATIVAS PREVISTA EN EL ARTíCULO 115 DE LA CONSTITUCIÓN
}

\author{
ANTONIO BAR CENDÓN \\ Catedrático de Derecho Constitucional \\ Universidad de Cantabria
}


SUMARIO

I. Preliminar. - Il. La disolución voluntaria en la Constitución de 1978.-III. UNA POSIBLE REFORMA. 


\title{
31. SOBRE UNA HIPOTÉTICA REFORMA DE LA POTESTAD DE DISOLUCIÓN DE LAS CÁMARAS LEGISLATIVAS PREVISTA EN EL ARTÍCULO 115 DE LA CONSTITUCIÓN
}

\author{
POR \\ ANTONIO BAR CENDÓN \\ Catedrático de Derecho Constitucional \\ Universidad de Cantabria
}

I. PRELIMINAR

La disolución de las Cámaras prevista en el art. 115 de la Constitución es lo que cabe denominar técnicamente como "disolución voluntaria»; es decir, aquella que se produce como producto de la voluntad no forzada jurídicamente del órgano competente para ello. Se distingue, en este sentido, del "fin natural" del mandato parlamentario, que en España tiene una duración de cuatro años para las dos Cámaras (arts. 68.4 y 69.6), y de la "disolución automática", que se produce como consecuencia juridicamente necesaria de la producción de un determinado supuesto constitucionalmente previsto. La Constitución Española de 1978 prevé solamente los supuestos de disolución automática: la que se produce al haber transcurrido dos meses desde la primera votación de investidura sin que se lograse el nombramiento de un nuevo Presidente del Gobierno (art. 99.5) - analizada en el trabajo dedicado al Tit. IV de la Constitución-, y la que tiene lugar cuando las Cámaras hubiesen decidido realizar una reforma total o sustancial de la Constitución (art. 168.1).

La previsión de la disolución voluntaria, si bien no es absolutamente imprescindible para la existencia de la forma parlamentaria de gobierno, sí puede decirse que es uno de sus elementos más caracterís- 
ticos '. De aquí, pues, que el constituyente español no dudase un solo momento a la hora de introducir este mecanismo en el texto de la Constitución ${ }^{2}$, en la medida en que lo que se estaba diseñando era precisamente una forma parlamentaria de gobierno, como hoy establece el art. 1.3 ( $" \mathrm{La}$ forma política del Estado español es la Monarquía parlamentarian).

Por otra parte, el mecanismo de la disolución voluntaria es un instrumento típico y profundamente arraigado de nuestro constitucionalismo histórico -como lo es también del británico-, hasta tal punto que puede afirmarse que la disolución voluntaria es en España la forma habitual de finalizar el mandato parlamentario. De hecho, desde la introducción de la forma de gobierno parlamentaria, en el primer tercio del siglo XIX, hasta nuestros dias -el sistema constitucional de 1978 incluido-, nunca unas Cortes llegaron a agotar el plazo constitucionalmente previsto para su mandato, siendo siempre disueltas con anterioridad. El constituyente de 1978, pues, al introducir la disolución voluntaria no ha hecho sino recoger una tradición plenamente asentada de nuestro parlamentarismo ${ }^{3}$.

Ahora bien, si la disolución voluntaria requiere, por definición, un ámbito de discrecionalidad, desde el punto de vista de la iniciativa, ello no quiere decir que no esté sujeta a toda una serie de reglas $y$ limitaciones, que suponen la garantía de su correcto ejercicio y de su no desviada eficacia. En este sentido, el Derecho comparado ofrece un amplio cuadro de regulaciones, que afectan al órgano capaz de adoptar la decisión de disolver, al procedimiento de disolución, a las circunstancias en que ésta se produce, y a los efectos de la misma.

En lo que se refiere al sujeto capaz para decretar la disolución, la generalidad de los textos constitucionales atribuyen formalmente esta potestad al Jefe del Estado, si bien la iniciativa reside casi siempre en el Primer Ministro ${ }^{4}$. Sin embargo, la disolución voluntaria puede ser decretada

1 La disolución voluntaria está prevista en todas las Constituciones parlamentarias europeas, con excepción de la de Noruega.

2 La disolución voluntaria figuró desde el primer momento en el borrador de la ponencia redactora del proyecto constitucional.

3 Véase a este respecto, G. BAYÓn CHACÓN: El derecho de disolución del Parlamento (Madrid: Universidad Central, 1935); A. BAR CENDóN: La disolución de las Cámaras legislativas en el ordenamiento constitucional español (Madrid: Congreso de los Diputados, 1989).

4 La disolución voluntaria es un mecanismo formalmente atribuido al Jefe del Estado de una manera más o menos autónoma y sin que se requiera expresamente la iniciativa del Primer Ministro, en Austria (art. 29), Bélgica (art. 71), Dinamarca (art. 32.2), Finlandia (art. 27), Francia (art. 12), Gran Bretaña, Grecia (en el supuesto del art. 41.1), Islandia (art. 24), Italia (art. 88), Liechtenstein (art. 48), Luxemburgo (art. 74), Mónaco (art. 27), Países Bajos (art. 64), y Portugal (arts. 136.e y 
de una manera libre, incondicionada, o de una manera restringida, o condicionada a la producción previa de determinadas supuestos.

La disolución voluntaria libre no lo es tanto, en más de una ocasión, no siendo infrecuente la exigencia de la consulta previa con determinados órganos. Así, en la actualidad, la consulta previa con los Presidentes de las Cámaras está prevista en Francia (art. 12) e Italia (art. 88); en Grecia se exige la consulta previa con el Consejo de la República en uno de los varios supuestos de disolución previstos (art. 41.1); y en Portugal se exige la consulta previa con el Consejo de Estado y con los partidos representados en la Asamblea (art. 136.e). Y, en lo que se refiere a la disolución voluntaria condicionada, los factores condicionantes, que pueden ser de muy diverso tipo - voto de censura o desconfianza parlamentaria, etc.- son, en realidad, un requisito habilitante que permite la disolución, pero no una imposición necesaria de la misma (si no sería una disolución automática). Cuando la disolución sigue a la producción de alguno de estos hechos habilitantes se le denomina técnicamente disolución sucesiva ${ }^{5}$.

Con respecto a las Cámaras afectadas por la disolución, si bien los supuestos de disolución (voluntaria) conjunta de ambas Cámaras por imperativo constitucional son muy excepcionales -está prevista en Islandia (art. 24) e Irlanda (art. 13.2) -6 , la posibilidad de disolución indistinta de una o de las dos Cámaras a la vez está prevista en Bélgica (art. 71), Italia (art. 88) y Países Bajos (art. 64), sistemas en los que el Senado es electivo

175). Lo que supone, por tanto, la mayoría de los sistemas europeos occidentales. Por el contrario, se requiere formal y explícitamente la propuesta o intervención del Primer Ministro en la iniciativa de la disolución - no sólo en el refrendo- en Alemania (art. 68.1), Grecia (art. 37.4 y en el supuesto del art. 41.2, que se refiere, en realidad, al Gobierno todo), Irlanda (art. 13.2.1. ${ }^{\circ}$, Malta (art. 77.2) y Suecia, donde, en realidad, la disolución la decide el Gobierno por sí mismo, sin la intervención del Rey (Cap. III, art. 4). En Lieschtenstein, además del Príncipe, el pueblo puede también pedir la disolución del Landtag a través de un referendum (art. 48).

5 La disolución voluntaria incondicionada se registra en la actualidad en las Constituciones de Austria, art. 29.1; Bélgica, art. 71; Dinamarca, art. 32.2; España, arts. 62.b y 115; Finlandia, art. 27; Francia, art. 12; Irlanda, arts. 13.2 y 16.3; Islandia, art. 24; Italia, arts. 88 y 89; Liechtenstein, art. 48; Luxemburgo, art. 74; Malta, art. 77; Mónaco, art. 27; Países Bajos, art. 64; Portugal, arts. 136.e y 175; y Suecia, Cap. III, art. 4. Mientras que la disolución voluntaria condicionada a la producción previa de determinados supuestos se registra en las Constituciones de Alemania Federal, art. 68.1; Dinamarca, art. 15.2; Grecia, arts. 37.4 y 41.1 y .2, y Suecia, Cap. VI, art. 5.

6 En Irlanda se trata de un caso especial de disolución conjunta diferida, dado que, si bien se disuelve sólo la Dail Eireann (asamblea de Irlanda), de acuerdo con el art. 13 de la Constitución, está disolución determina automáticamente la necesidad de la elección de un nuevo Seanad Eirean (Senado de Irlanda) en el plazo de 90 días (art. 18.8). 
y, como en España, tiene unas funciones muy similares a las de la Cámara Baja. Por el contrario, sólo se produce la disolución de la Cámara Baja, quedando excluida la de la Cámara Alta, en aquellos sistemas en los que esta última procede de una representación indirecta o corporativa, o tiene un carácter netamente territorial, como son los casos de Alemania Federal (art. 68.1), Austria (art. 29.1), Francia (art. 12) y Gran Bretaña. Por lo demás, la disolución es también admitida en la práctica totalidad de los casos de Parlamentos unicamerales ?.

Finalmente, es frecuente la imposición de otro tipo de limitaciones, de carácter temporal y de oportunidad. Así, en lo que se refiere a las limitaciones temporales, lo que se trata de evitar es la reiteración sucesiva de disoluciones que impida el normal funcionamiento del Parlamento, y para ello se establece la necesidad de que transcurra un determinado período de tiempo entre una disolución y la siguiente. Este plazo suele ir desde un año, que es lo que se establece en las actuales Constituciones francesa (art. 12) y griega (art. 41.4), hasta períodos menores. Así, en Portugal este plazo se reduce a seis meses (art. 175.1), y en Suecia a tres meses desde la primera reunión de la Cámara (Cap. III, art. 4). En Dinamarca no se puede volver a disolver antes de que el nuevo Gobierno se presente a la confianza de la Cámara (art. 32.2), y en Austria, con igual sentido -y con un precepto muy similar al previsto en el art. 81 de la Constitución española de 1931-, sólo se puede disolver una vez por el mismo motivo (art. 29.1); precepto recogido tambien en el mencionado art. 41.4 de la Constitución griega de 1975 . Y, en lo que se refiere a las limitaciones de oportunidad, suele establecerse la prohibición de disolver en determinadas circunstancias, principalmente durante la vigencia de los estados excepcionales. Así lo establecen, por ejemplo, la Constitución francesa de 1958 (art. 16), la Ley Fundamental de Bonn, tras su reforma de 1968 (art. 115h.3) y la Constitución Portuguesa de 1976, tras su reforma de 1982 (art. 175.1).

\section{LA DISOLUCIÓN VOLUNTARIA EN LA CONSTITUCIÓN DE 1978}

De todo este somero panorama normativo que inspira la regulación de la disolución voluntaria en el Derecho comparado, se puede decir que

$\therefore$ Supuestos de disolución voluntaria de Parlamentos unicamerales son los casos de Dinamarca (art. 32), Finlandia (art. 27), Grecia (art. 41), Liechtenstein (art. 48), Luxemburgo (art. 74), Mónaco (art. 27), Portugal (art. 136.e) y Suecia (Cap. III, art. 4). 
la Constitución española ha recogido lo que supone el esquema esencial que caracterizaría el modelo básico de disolución voluntaria.

Así, el art. 115 establece una disolución voluntaria a) de iniciativa gubernamental, cuya "responsabilidad exclusiva" se atribuye al Presidente del Gobierno, pero b) cuya decretación corresponde formalmente al Rey. La iniciativa c) requiere la previa deliberación del Consejo de Ministros; $d$ ) la disolución puede afectar a una sola o a las dos Cámaras a la vez; $y$ e) el decreto de disolución debe fijar la fecha de las elecciones.

Al lado de estos requisitos positivos se establecen también una serie de limitaciones, que entran de lleno igualmente en el cuadro común de las regulaciones descritas: a) la propuesta de disolución no podrá presentarse cuando esté en trámite una moción de censura; $b$ ) no procederá una nueva disolución antes de que transcurra un año desde la anterior; y $c$ ) no podrá procederse a la disolución del Congreso mientras esté declarado alguno de los estados excepcionales previstos en el artículo 116, quedando automáticamente convocadas las Cámaras si no estuvieran en período de sesiones, y asumiendo la Diputación Permanente del Congreso sus competencias, si ésta Cámara no pudiese reunirse por encontrarse disuelta o haber finalizado su mandato (art. 116.5).

\section{UNA POSIBLE REFORMA}

Dado, pues, lo común de la regulación constitucional, que se atiene a las reglas generales experimentadas en el Derecho comparado y en el propio constitucionalismo histórico español; dado lo adecuado de la existencia misma del instituto de la disolución, acorde con el carácter parlamentario de la presente forma de gobierno; y dado, en fin, el principio del mínimo cambio posible, de proponer sólo las reformas imprescindibles para una hipotética mejora del texto constitucional, entiendo que no merece la pena ir más allá de la reconsideración de la posibilidad de disolver el Senado, prevista en el apartado 1 del art. 115.

Efectivamente, el estudio en profundidad de la previsión constitucional de la disolución voluntaria nos llevaría al análisis de una amplia problemática, que extiende sus ramificaciones tanto al ámbito del Poder Legislativo, como al del propio Poder Ejecutivo. Sin embargo, buena parte de esta problemática es de carácter puramente interpretativo y encuentra fácil solución en una exégesis sistemática del texto constitucional. (Así, cuestiones tales como la autonomía decisora del Rey en este terreno; posibilidad 
de la disolución en caso de moción de censura o de cuestión de confianza; posibilidad de la disolución voluntaria inmediatamente después de una disolución automática, o viceversa; ¿se aplica la prohibición de disolver tras una disolución anterior en todo caso, o sólo cuando hubiese afectado a las dos Cámaras?; tipo de disolución al que se refiere la prohibición del art. 116.5 , etc.). De todo ello, $v$ de la problemática en general que plantea la disolución, me ha ocupado ya en otro lugar. A lo allí expuesto me remito ${ }^{8}$.

Más interés tienen los problemas que plantean los efectos de la disolución, tanto con respecto al Gobierno como con respecto a la Cámara o Cámaras disueltas. Sin embargo, ello excede el marco de este análisis, dado que supondría entrar de lleno en el terreno de la actividad parlamentaria y de las consecuencias del final del mandato legislativo, o en el terreno de la actividad gubernamental, campos que corresponden a otros apartados de la Constitución y que son objeto de otras ponencias en este congreso.

En todo caso, y con respecto al Gobierno, es de destacar que, de acuerdo con el texto constitucional, $y$ en contra de lo que es una regulación común en el Derecho comparado, la disolución no produce por sí misma el cese de la actividad ordinaria del Gobierno que disuelve y su entrada" "en funciones", o en mero despacho de los asuntos de trámite, sino que, según la previsión del art. $101-y$ en lo que a este tema respecta-, el Gobierno sólo cesa "tras la celebración de elecciones generales" ${ }^{9}$. Ello le permite, en términos puramente teóricos, ocupar una injustificada situación de superioridad sobre las Cámaras, dado que él permanecería en la absoluta integridad de sus poderes, mientras que las Cámaras disueltas quedarían en situación de práctico vacío, hasta la celebración de las elecciones y la constitución de las nuevas Cámaras.

En definitiva, pues, el tema clave que aquí se plantea es la posibilidad, o no, de la disolución del Senado. La previsión del art. 115.1, que admite la disolución de ambas Cámaras, simultánea o separadamente, está pensada desde la perspectiva del Senado que diseñaba el propio constituyente; es decir, una Cámara nominalmente de representación territorial, pero, en la realidad - por propia imperativo constitucional-, de representación popular ordinaria, similar a la del Congreso, aunque obtenida a tra-

- Vid. A. BAR CEndón: La disolución de las Cámaras legislativas en el ordenamiento constitucional español. (Madrid: Congreso de los Diputados, 1989).

9 La conversión del Gobierno en un órgano de trámite de los asuntos corrientes - "en funciones", en la terminología española-, tras la disolución y hasta la formación del nuevo, está expresamente prevista en Alemania (art. 69.3), Dinamarca (art. 15), Irlanda (art. 28.11.2. ${ }^{\circ}$ y Portugal (art. 189.5). Véase lo dicho a este respecto en el artículo dedicado al Tít. IV de la Constitución en esta misma Revista. 
vés de diferente procedimiento electoral. Una Cámara, en definitiva, de segunda lectura, de componente y funciones muy similares a las del Congreso, a la cual, por tanto, no había por qué excluir de la regla general de la disolución.

Ahora bien, si el Senado que se pretende es una Cámara de auténtica representación territorial, con un proceso de elección diferente y funciones específicos en esta línea, es evidente que debería ser excluido de la posibilidad de aplicarle la disolución voluntaria. Y ello, porque su representación lo sería de los elementos estables de la estructura territorial compleja del Estado - las Comunidades Autónomas-, y no de la población en general, sometida a los cambios y variaciones de los intereses políticos particulares, cuyo reflejo propio es el Congreso de los Diputados.

En este sentido, pues, el párrafo 1 del art. 115 debería ser modificado, adaptándolo a esta nueva configuración del Senado como Cámara estable de representación territorial, y excluyendo la posibilidad de su disolución. Así, la nueva redacción debería ser la siguiente:

"1. El Presidente del Gobierno, previa deliberación del Consejo de Ministros, y bajo su exclusiva responsabilidad, podrá proponer la disolución del Congreso de los Diputados, que será decretada por el Rey. El decreto de disolución fijará la fecha de las elecciones». 